\title{
Influence of the Precipitating Reagents and Dispersants on the Formation Nano-Aluminum Hydroxide
}

\author{
G. Sarsenbay $^{1}$, L. A. Myltykbaeva ${ }^{2}$, R. A. Abdulwalyev ${ }^{1}$, B. M. Sukurov ${ }^{1}$ \\ ${ }^{1}$ Center of the Earth Sciences, Metallurgy and Benefication, JSC, Science and Education Ministry \\ of the Republic of Kazakhstan, Almaty, Kazakhstan \\ ${ }^{2}$ National Science and Technology Holding “Parasat”, JSC, Science and Education Ministry \\ of the Republic of Kazakhstan, Astana, Kazakhstan \\ Email: mer-pa@mail.ru
}

Received July 2013

\begin{abstract}
The influence of the precipitating reagents and dispersants on the formation of nano-aluminum hydroxide from sodium aluminate solution by chemical precipitation was investigated. The influence of the dispersed seeds on the decomposition process was investigated too. The alkaline aluminate solutions were used as original solutions with a concentration of $\mathrm{Al}_{2} \mathrm{O}_{3}$ having $14.78 \mathrm{~g} / \mathrm{dm}^{3}, \alpha_{\mathrm{k}}-1.6$ and $127 \mathrm{~g} / \mathrm{dm}^{3}, \alpha_{\mathrm{k}}-1.6$. For the precipitation processes there were used following precipitating reagents-solutions $\mathrm{HCl}, \mathrm{NaHCO}_{3}$ and $\mathrm{NH}_{4} \mathrm{HCO}_{3}$ with a concentration of $80 \mathrm{~g} / \mathrm{dm}^{3}$, dispersants-PEG 6000, $\left(\mathrm{NaPO}_{3}\right)_{6}$ and Tween 20. For the decomposition process the dispersed seeds and factories seeds were used. Structural studies of the aluminum hydroxide particles were carried out by means of the electron-probe microanalysis and scanning electron microscopy, and phase composition of products was determined by means of X-ray diffraction analysis. Ammonium bicarbonate and Tween 20 were determined as the optimal precipitating reagent and dispersant, correspondingly, resulting in dispersed aluminum hydroxide, which is used as a seed in the decomposition process. It was established that this product in form of dispersed seed considerably reduces the duration of the decomposition process; the maximal decomposition of solution (73.9\%) was observed after injection of dispersed aluminum hydroxide into solution. The final aluminum hydroxide having $90 \%$ of particles less than 100 nanometers was obtained within 7 hours of steady decreasing temperature from $70^{\circ} \mathrm{C}$ to $48^{\circ} \mathrm{C}$.
\end{abstract}

Keywords: Nano-Aluminum Hydroxide; Precipitating Reagents; Dispersants; Alkaline Aluminate Solution; Precipitation; Particles; Decomposition; Particle Diameter

\section{Introduction}

Nowadays more than $90 \%$ of produced alumina are directed to the production of aluminum, and the demand for special types of alumina permanently grows with the pace of development of the industry and the economy [1]. Usage of special aluminas such as nano-dispersed alumina enable the significantly improved properties of materials with expansion of the area of applications. It can form the basis for the creation of fundamentally new devices on nanometric scale bringing the considerable economic benefit because of their special properties [2]. Materials containing nano-alumina are widely used in the aerospace, nuclear, power, metallurgy, electronics, biochemical industry, etc [3].

Production of nanodispersed alumina around the world in recent years has become a major focus in the field of new materials based on alumina. Analysis of literature data and patent information show that the raw materials for nano-alumina are in general the expensive alkoxides or inorganic salts and the commercial products of alumina production. It leads to negative effect on the economical indexes of production [4-6]. Associated production of nano-alumina in alumina production can greatly raise the price of commercial products with resulting profit per ton higher to 10 - 100 times compared to indexes in case of metallurgical alumina.

There are physical, chemical and combined methods to obtain nano-alumina. The easiest and cheapest way is the method of chemical precipitation from solution of aluminum salt. This way the precipitating reagents and dispersants cause variation in particle sizes and other properties of the resulting aluminum hydroxide. Precipitation of solid aluminum hydroxide from the solution of aluminate may occur in alkaline, acid and neutral media. In this paper we investigate the process of chemical precipitation of nanoparticles of aluminum hydroxide from alkali aluminate solution to identify production condi- 
tions for decomposition process using the dispersed seed $[7,8]$.

\section{Materials and Methods}

For the precipitation processes the sodium aluminate solution was used with concentration $\mathrm{Al}_{2} \mathrm{O}_{3}-14.78$ $\mathrm{g} / \mathrm{dm}^{3}, \alpha_{\mathrm{k}}-1.6$, for decomposition the solution was used with concentration $\mathrm{Al}_{2} \mathrm{O}_{3}-127 \mathrm{~g} / \mathrm{dm}^{3}$ and $\alpha_{k}-1.6$. There were used $\mathrm{NaHCO}_{3}, \mathrm{NH}_{4} \mathrm{HCO}_{3}$ and $\mathrm{HCl}$ as precipitating reagents, and PEG 6000, $\left(\mathrm{NaPO}_{3}\right)_{6}$ and Tween20 as dispersants. For washing of products the distilled water and ethyl alcohol $-\mathrm{C}_{2} \mathrm{H}_{5} \mathrm{OH}$ were used.

Experiments were conducted in laboratory facility for the precipitation and decomposition.

In the experiments on precipitation of sodium aluminate solution was placed in a flask where the mechanical stirring is carried. Precipitating reagent $\left(\mathrm{HCl}, \mathrm{NaHCO}_{3}\right.$, $\mathrm{NH}_{4} \mathrm{HCO}_{3}$ ) was injected to solution of sodium aluminate with a concentration of $80 \mathrm{~g} / \mathrm{dm}^{3}$ by titration. The process of stirring continued for 10 minutes after the titration; the final $\mathrm{pH}$ of the resulting solution was 10 .

In the experimental parts of $\mathrm{B}$, to sodium aluminate dispersants-PEG 6000, $\left(\mathrm{NaPO}_{3}\right)_{6}$ and Tween-20 were added in the amount $3 \%$ by weight of the sodium aluminate, as an precipitating reagent $\mathrm{NH}_{4} \mathrm{HCO}_{3}$ was used.

The experiments of decomposition were carried out in the decomposer under hydrothermal conditions. The initial temperature was about $70^{\circ} \mathrm{C}$ with a steady lowering to $48^{\circ} \mathrm{C}$; the process duration was 24 hours; seeding ratio was 2:1.

Filtration of the pulp was carried out in the centrifuge, the solid phase washed with distilled water and ethanol. Structures and element compositions of the solid precipitates were determined using JEOL electron-probe microanalyzer JXA-8230, and phase compositions-using X-Ray Bruker diffractometer D8 Advance with radiation $\alpha-\mathrm{Cu}$.

\section{Results and Discussion}

A. The influence of precipitating reagents on formation of aluminum hydroxide nanoparticles

The influence of precipitating reagents on stucture of aluminum hydroxide is shown in Figure 1. In case of precipitation with hydrochloric acid the resulted srtucture of aluminum hydroxide has agglomerated form (Figure 1(a)), whereas the particles of aluminum hydroxide precipitated by sodium bicarbonate (Figure 1(b)) and ammonium bicarbonate (Figure 1(c)) demonstrate the agglomerated and finely dispersed forms in general. The average diameters of particles and the percentage distribution of the particles formed are shown in Table 1.

Table 1 shows the strong influence of precipitating reagents on size distribution of particles. In case of
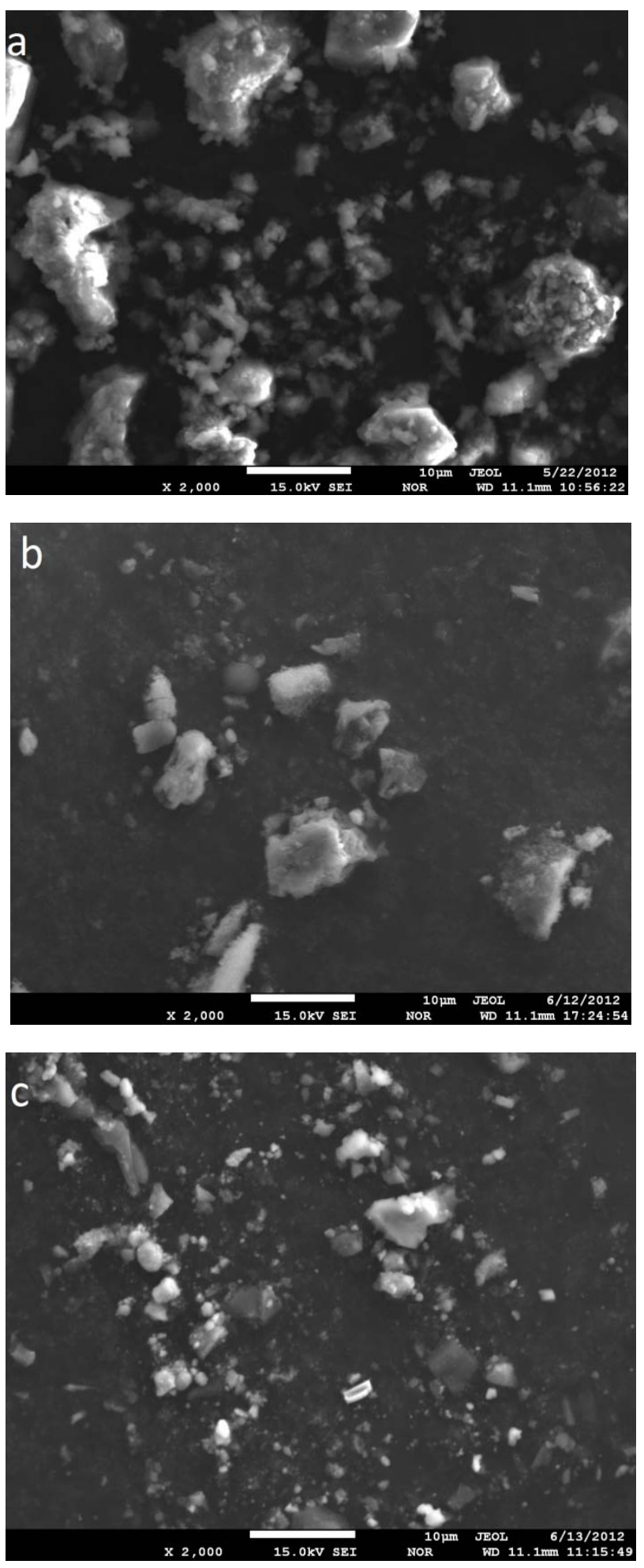

Figure 1. Structure of aluminum hydroxide particles depending on the precipitating reagent: $\mathrm{a}-\mathrm{HCl}, \mathrm{b}-\mathrm{NaHCO}_{3}$, and $\mathrm{c}-\mathrm{NH}_{4} \mathrm{HCO}_{3}$.

precipitation of aluminum hydroxide using hydrochloric acid the particles have average diameter of $1.15 \mu \mathrm{m}$, share of particles with a diameter of $0.1 \mu \mathrm{m}$ is $3 \%$ of the 
Table 1. Influence of the precipitating reagents on size distribution of aluminum hydroxide particles.

\begin{tabular}{cccccc}
\hline \multirow{2}{*}{$\begin{array}{c}\text { Precipitating } \\
\text { reagent }\end{array}$} & \multicolumn{4}{c}{$\begin{array}{c}\text { Share of particles by } \\
\text { diameter }(\mathrm{d}, \mu \mathrm{m}), \%\end{array}$} & $\begin{array}{c}\text { Average } \\
\text { diameter, } \mu \mathrm{m}\end{array}$ \\
\cline { 2 - 5 } & 0.1 & 0.238 & $0.238-1$ & $>1$ & \\
\hline $\mathrm{HCl}$ & 3 & 17 & 40 & 40 & 1.15 \\
$\mathrm{NaHCO}_{3}$ & 10 & 8 & 54 & 28 & 2.16 \\
$\mathrm{NH}_{4} \mathrm{HCO}_{3}$ & 52 & 36 & 8 & 4 & 0.275 \\
\hline
\end{tabular}

total. When sodium bicarbonate was used the average particle diameter is about $2.16 \mu \mathrm{m}$, and $10 \%$ of the produced particles have a diameter of $0.1 \mu \mathrm{m}$. The most promising result on the optimal conditions for the process of precipitation was for ammonium bicarbonate where $52 \%$ of the precipitated hydroxide particles had diameter not higher than $100 \mathrm{~nm}$. The result of the experiments is related to the instability of ammonium bicarbonate solution permitting to control the diameter of aluminum hydroxide particle. Moreover the emitting gas phase prevents agglomerate formation.

B. Influence of dispersants on formation of nanoparticles of aluminum hydroxide from sodium aluminate solution

The influence of dispersants on stucture of aluminum hydroxide is shown in Figure 2.

In case of PEG 6000 the average diameter of the aluminum hydroxide particles is about $0.413 \mu \mathrm{m}$, and share of particles below $100 \mathrm{~nm}$ is $60 \%$; the share below 200 $\mathrm{nm}$ is $35 \%$ of the total quantity (Figure 2(a)). After experiment where Tween 20 was used the share of particles below $0.1 \mu \mathrm{m}$ was $65 \%$ and share below $0.2 \mu \mathrm{m}$ was $12 \%$ with average particle diameter about $0.48 \mu \mathrm{m}$ (Figure 2(b)). The experiments using sodium polyphosphate resulted to the average particle diameter $1.49 \mathrm{~mm}$, with $25 \%$ share of the diameter below $0.1 \mu \mathrm{m}$ and $16 \%$ share having diameter below $0.2 \mu \mathrm{m}$ (Figure 2(c)).

Results for the experiments on the deposition of aluminum hydroxide using the dispersants are given in Table 2.

The data in Table 2 shows that the addition of Tween 20 to solution of sodium aluminate can precipitate $65 \%$ of aluminum hydroxide in form of nanosized particles.

In disperse system dispersant is adsorbed on the particle surfaces of precipitating substance reacting with the particles and forming a protective layer, and thus preventing the agglomeration between particles. The effect of dispersant is associated with the HLB value. Literature study shows that use of a dispersant having HLB value about 10 can provide nano alumina [9]. In this paper the dispersant Tween 20 was used with a value of HLB about 8.6.

Analysis of the content of the experimental filtrates using dispersant-Tween 20 and precipitant-ammonium bicarbonate showed that the solutions obtained after filtration contains less alumina with minor impurities,
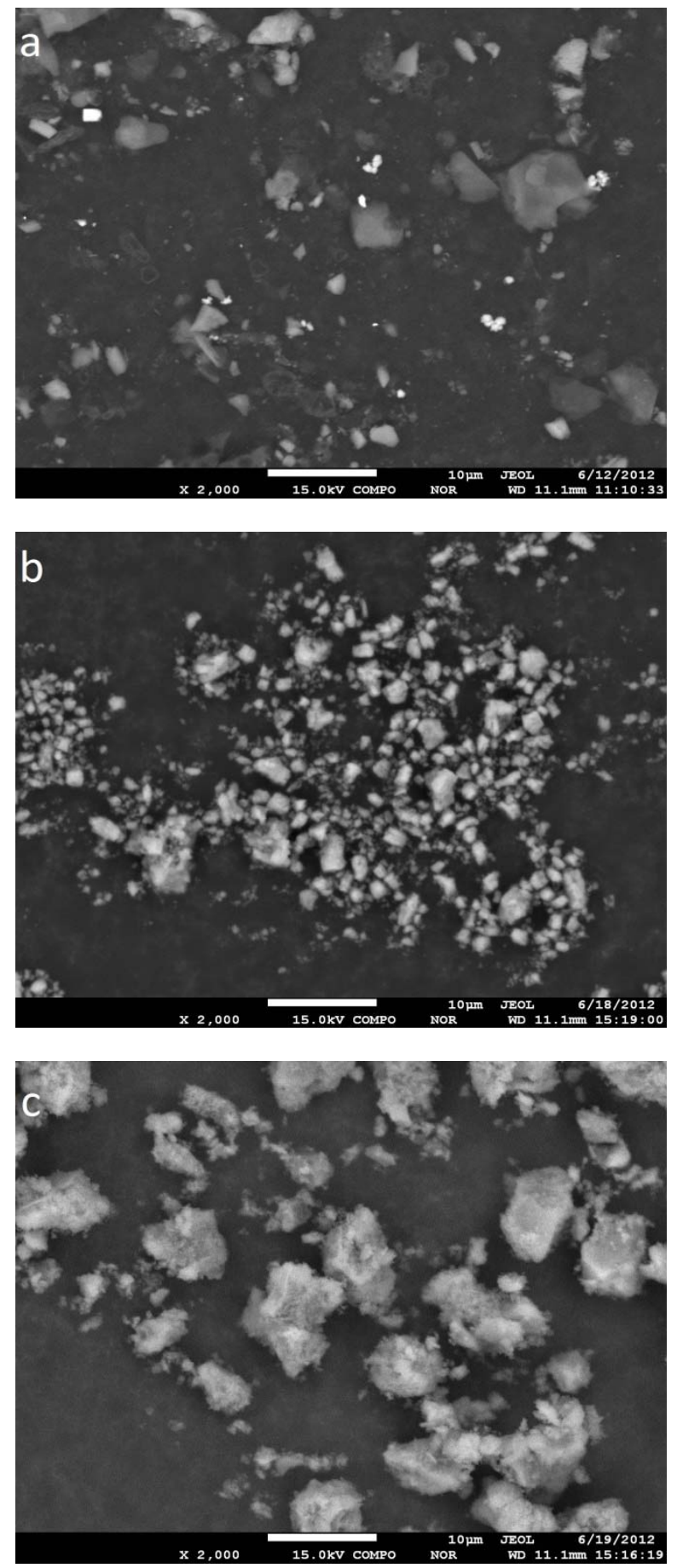

Figure 2. Structure of aluminum hydroxide particles depending on the addition of dispersants: a-PEG 6000, bTween 20, and $\mathrm{c}-\left(\mathrm{NaPO}_{3}\right)_{6}$.

Table 2. Influence of the dispersants on size distribution of aluminum hydroxide particles.

\begin{tabular}{ccc}
\hline Dispersant & \multicolumn{2}{c}{ Experimental results } \\
\hline & Average diameter, $\mu \mathrm{m}$ & Share of nanoparticles, \% \\
\hline PEG 6000 & 0,413 & 60 \\
TWEEN 20 & 0,48 & 65 \\
$\left(\mathrm{NaPO}_{3}\right)_{6}$ & 1,49 & 25 \\
\hline
\end{tabular}


and being alkaline solutions of sodium, they can be used for leaching.

C. Influence of dispersed seeds on the process of decomposition

In the process of decomposition of sodium aluminate solution the adding of seed considerably influences on the dispersion of hydroxides obtained. A number of experiments were performed to clear the influence of the dispersed seeds on the degree of decomposition of sodium aluminate solution and on the dispersion of aluminum hydroxide obtained. Two types of seed were used a fine aluminum hydroxide preliminary produced under the certain conditions (Part A and B), and commercial aluminum hydrate supplied from plant.

Experiments were carried out using dispersed seed and plant seed with the ratio of 2:1. The conditions and results of the experiments are shown in Figure 3.

The data of experiments show that in the decomposition of solution with concentration $\mathrm{Al}_{2} \mathrm{O}_{3} 127 \mathrm{~g} / \mathrm{dm}^{3}$ and $\alpha_{k} 1.5$ the speed and degree of decomposition are higher when dispersed seed was used (curve 1) compared to case of commercial seed (curve 2). The degree of maximal decomposition-73.9\% was obtained after decomposition for 7 hours; the srtucture of the resulting sediment is shown in Figure 4.

Estimations for Figure 4 show that the $90 \%$ of obtained aluminum hydroxide consist in the dispersed form with a minor agglomeration.

Figure 5 shows the result of energy-dispersive spectrometry analysis for element compositions of the resulted aluminum hydroxide (in mass \%): $\mathrm{Al}-32.90$; O66.11; $\mathrm{Si}-0.61 ; \mathrm{Na}-0.38$. The amounts of impurities in sediment are rather small.

The phase composition of the deposit was identified by means of X-ray diffraction analysis: gibbsite- $\mathrm{Al}(\mathrm{OH})_{3}-$ $69.7 \%$ and bayerite- $\mathrm{Al}(\mathrm{OH})_{3}-30.3 \%$ (Figure 6).

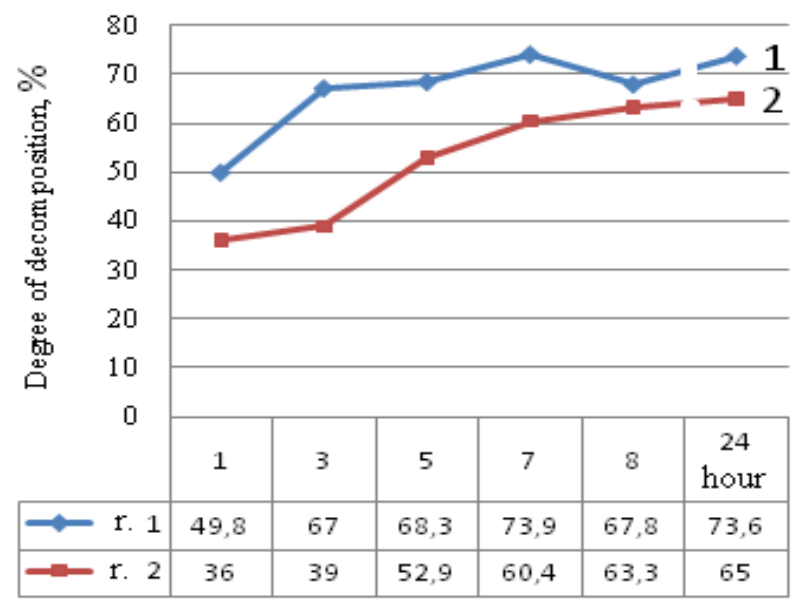

Figure 3. Degree of solution decomposition for different types of seed. 1. ratio 2:1 (dispersed seed); 2. ratio 2:1 (commercial seed).

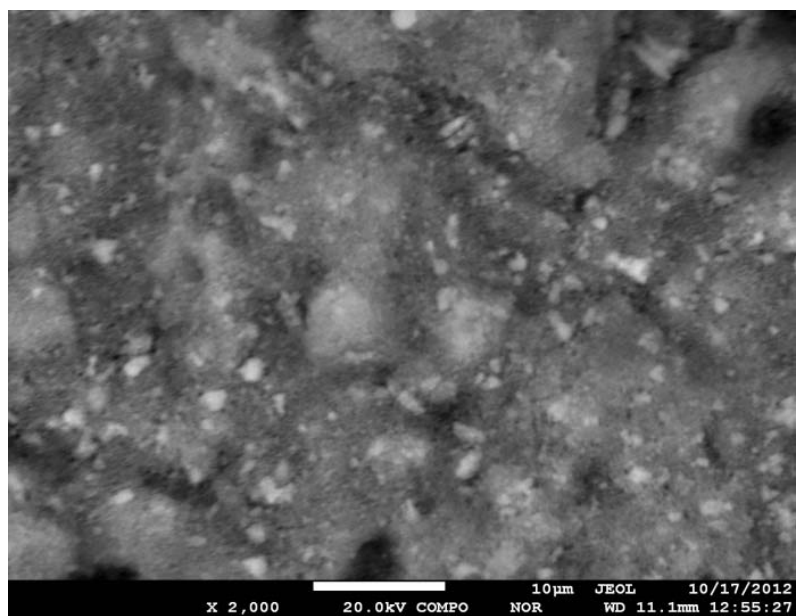

Figure 4. Particles of sediment obtained using a dispersed seed.
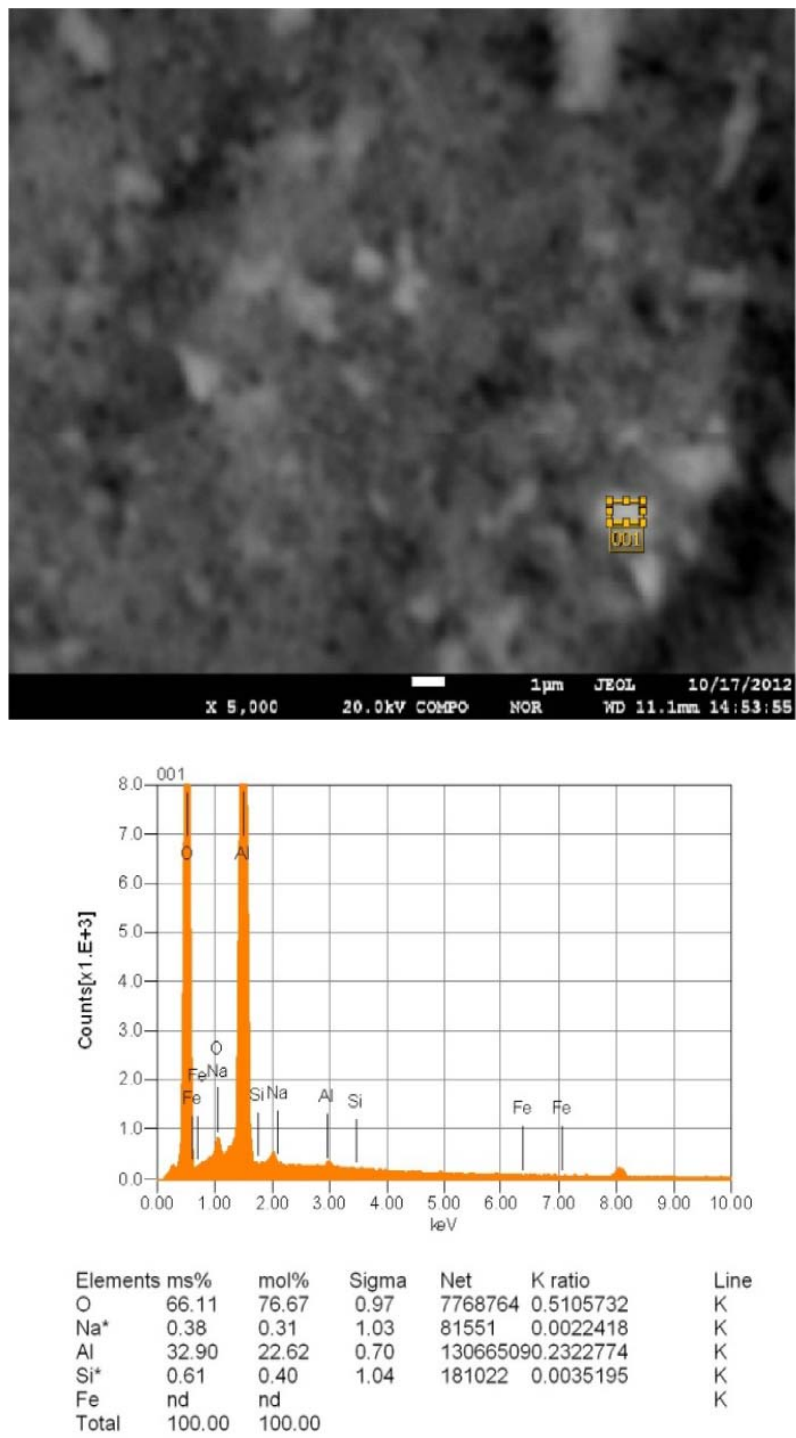

Figure 5. Energy-dispersive spectrometry analysis (EDS) of sediment obtained. 


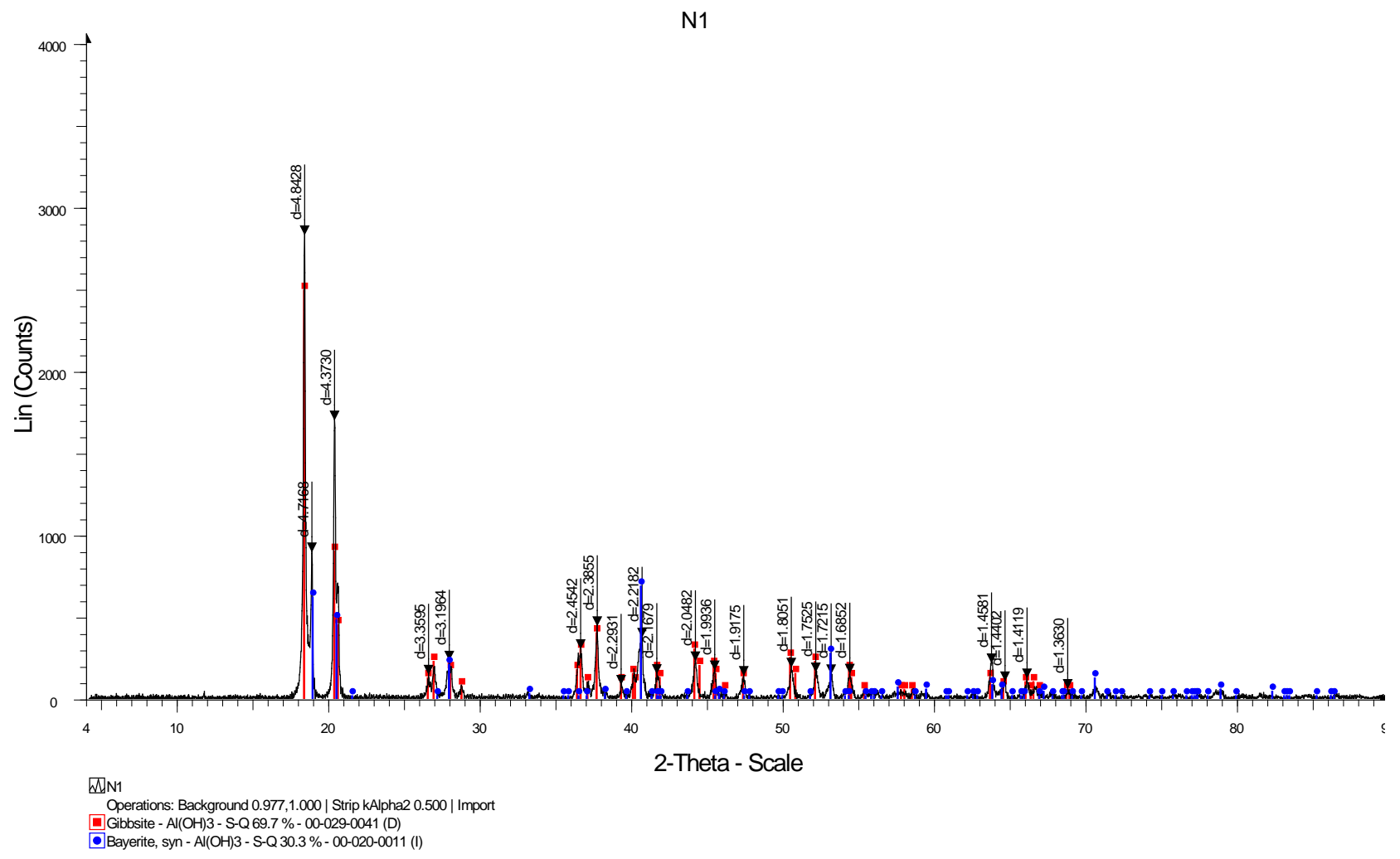

Figure 6. The X-Rays diffraction pattern of sediment obtained.

\section{Conclusions}

Based on the studies and the results obtained the following conclusions can be made.

1) Best results of precipitation of dispersed aluminum hydroxide are achieved when ammonium bicarbonate and Tween-20 were used as precipitating reagent and as a dispersant, correspondingly. Aluminum hydroxide was obtained with $65 \%$ of particles not exceeding $100 \mathrm{~nm}$.

2) It was established that the seed in form of fine-dispersed aluminum hydroxide permits to accelerate and increase the degree of decomposition. The degree of solution decomposition with adding of dispersed seed can reach to $73.9 \%$ for 7 hours under hydrothermal conditions; under these conditions aluminum hydroxide was obtained with $90 \%$ of particles not exceeding $100 \mathrm{~nm}$.

3) The experimental results confirm that the semi-finished product of alumina production in form of aluminate solutions can serve as a promising source to obtain nano alumina.

\section{REFERENCES}

[1] V. V. Ivanov, "Nanopowders Are Needed and Demanded for Modern Market,” Russian Nanotechnology, Vol. 4, No. 1, 2009, pp. 22-26.

[2] M. V. Alfimov, "The Immediate Prospects of Nanotechnology,” Russian Nanotechnology, Vol. 3, No. 5-6, 2008. pp. 1-2.

[3] P. A. Storozenko, "Nanopowders-Technology the Present Time,” Russian Nanotechnology, Vol. 4, No. 1-2, 2009, pp. 10-15.

[4] O. V. Almyasheva, E. N. Korytkova and A. V. Maslov, "Preparation of Aluminum Oxide Nanocrystals under Hydrothermal Conditions,” Inorganic Materials, Vol. 41, No. 5, 2005, pp. 460-467. http://dx.doi.org/10.1007/s10789-005-0152-7

[5] G. P. Panasiuc, V. N. Belan and I. L. Inroshilov, "The Change of Hydrargillite-Boehmite,” Inorganic Materials, Vol. 46, No. 5, 2010, pp. 831-837.

[6] A. T. Ibragimov and S. V. Budon, "The Development of Technology of Production of Alumina from Bauxite Kazakhstan,” Pavlodar, 2010, p. 304.

[7] G. Sarsenbay, L. A. Myltykbaev, R. A. Abdulwalyev and S. B. Satylganova, "Develop Nanotechnology Alumina Production Will Promote the Economy of Kazakhstan," Industry of Kazakhstan, No. 8, 2012, pp. 48-51.

[8] G. Sarsenbay, L. A. Myltykbaev, R. A. Abdulwalyev and S. B. Satylganova, "Influence of the Precipitation Reagent on the Formation of Nanoparticles Aluminum Hydroxide," Comprehensive Utilization of Mineral Resources, No. 4, 2012, pp. 20-25.

[9] Y. C. Zhang, S. O. Chen, et al., "Investigation of the Agglomeration Nano Alumina by Chemical Precipitating Process,” Materials Review, Vol. 21, No. VIII, 2007, pp. 44-46,53. 